\title{
Lactoferrin immunoexpression in endometrial carcinomas: Relationships with sex steroid hormone receptors (ER and PR), proliferation indices (Ki-67 and AgNOR) and survival
}

\author{
GIUSEPPE GIUFFRÈ, FRANCESCO ARENA, ROSA SCARFÌ, \\ ANGELA SIMONE, PAOLO TODARO and GIOVANNI TUCCARI \\ Department of Human Pathology, University of Messina, A.O.U. 'Policlinico G. Martino', I-98125 Messina, Italy \\ Received February 24, 2006; Accepted April 27, 2006
}

\begin{abstract}
We have investigated Lf immunoexpression as well as its biological meaning in 71 formalin-fixed, paraffinembedded surgical samples of endometrial carcinomas (EC); 64 EC were endometrioid type, whereas 7 were non-endometrioid carcinomas. Immunohistochemistry was performed by primary antibodies against Lactoferrin (Lf), estrogen receptor (ER), progesterone receptor (PR) and Ki-67 antigen. Quantification of Lf immunoreactivity was performed using an intensity-distribution (ID) score. Moreover, the AgNOR technique according to guidelines of the Committee on AgNOR Quantification was used to assess the proliferation rate (NORA). A variable expression of $\mathrm{Lf}$ was revealed in 43 cases (61\%) of EC. Endometrioid type carcinoma showed a significant higher Lf ID-score than non-endometrioid type; in contrast, no relationships were demonstrated between Lf immunoexpression and histologic grade, stage, clinical course as well as proliferative activity of EC. Moreover, a significantly higher Lf ID-score was encountered in ER-positive carcinomas. Survival analysis in EC indicated the architectural, nuclear and combined histologic grades as well as the stage, PR, Ki-67 and NORA as significant parameters. The utilization of Lf as a prognostic marker, able to identify patients at different risk of death, or alternatively, its clinical application as therapeutic agent, must be considered with great caution.
\end{abstract}

\section{Introduction}

Lactoferrin (Lf), an $80-\mathrm{kDa}$ basic glycoprotein, is a member of the transferrin family of iron-binding proteins which was originally isolated from human milk (1-3). By radioimmunological and immunoenzymatic procedures, $\mathrm{Lf}$ has been detected

Correspondence to: Professor Giovanni Tuccari, Department of Human Pathology, Azienda Ospedaliera Universitaria, 'Policlinico G. Martino', pad. D, I-98125 Messina, Italy

E-mail: tuccari@unime.it

Key words: endometrial carcinoma, lactoferrin, AgNORs, Ki-67, steroid hormone receptors in many biological fluids and secretions as well as in human fetal and adult tissues (4-11). By immunohistochemistry, the distribution of Lf has been investigated in normal human tissues such as stomach, kidney, lung, pancreas, liver, bone marrow (6) and uterine endometrium $(10,12)$.

In humans, serum concentrations and expression of Lf by endometrial tissue obtained from women in both proliferative and secretive phases have been analysed (13); either serum Lf concentrations or immunohistochemical staining for $\mathrm{Lf}$ were found greater during the proliferative phase than the secretory one (13). However, the physiological role of $\mathrm{Lf}$ as an autocrine stimulator of endometrial epithelium cell proliferation has been previously demonstrated in the mouse (14) and, more recently, in human patients (15). Moreover, although it is well known that estrogen and progesterone play an important role in the proliferation and differentiation of endometrium, a recent paper has established that also Lf expression in the uterine endometrium is up-regulated by estrogen (16).

Taking into consideration these findings and the numerous reports concerning the $\mathrm{Lf}$ immunolocalization in human tumours, we decided to investigate the immunohistochemical distribution pattern of Lf in endometrioid and non-endometrioid carcinomas of the uterus; moreover, the possible correlations between the presence of $\mathrm{Lf}$ and sex steroid hormone receptor (ER and PR) status, proliferation indices (Ki-67 and AgNOR) as well as survival time have been also investigated.

\section{Materials and methods}

Patients and materials. Surgical samples from 71 patients who underwent total abdominal hysterectomy and bilateral salpingo-oophorectomy for endometrial carcinomas (EC) were selected from files of our Department and included in this study. The mean age of the patients at the time of diagnosis was 63.8 years (range 38-84 years). Data concerning followup and cause of death were obtained from city registry offices. Histological classification of tumours was based on the World Health Organization system (17); in particular, 64 EC were endometrioid type, whereas 7 were non-endometrioid carcinomas (1 mucinous adenocarcinoma; 4 serous adenocarcinomas; 2 clear cell adenocarcinomas). The surgical-pathologic staging was performed according to the International Federation of Gynecology and Obstetrics classification (17); 
in detail, 48 cases were in stage I, 12 in stage II, 8 in stage III and 3 in stage IV. Moreover, the combined architectural/ nuclear grading - Rule 2 suggested by the Gynecologic Oncology Group (18) was also performed; 40 cases were grade 1,13 grade 2 and 18 grade 3 .

All samples were fixed in $10 \%$ neutral formalin for $24 \mathrm{~h}$ at room temperature (RT) and then embedded in paraffin at $56^{\circ} \mathrm{C}$. From each tissue block, serial $3-\mu \mathrm{m}$-thick sections were cut and mounted on silane-coated glasses, then dewaxed in xylene and rehydrated in graded ethanols. One section was subjected to haematoxylin and eosin (H\&E) staining, the others were utilized for immunohistochemical and histochemical procedures.

Immunohistochemical analysis. The immunoreactions were performed utilising primary antibodies against Lf (Rabbit Anti-Human Lactoferrin; DakoCytomation, Denmark; 1:300), estrogen receptor (ER) (MAb ER, 1D5, DBA, Italy; 1:10), progesterone receptor (PR) (MAb PgR-ICA; Abbott Laboratories, USA; 1:10) and Ki-67 antigen (MIB-1; DakoCytomation; 1:200). Antigen retrieval, by heating slides placed in $0.01 \mathrm{M}$ citrate buffer $\mathrm{pH} 6.0$ in a microwave oven for $3 \times 5 \mathrm{~min}$, was perfomed before adding all primary antibodies but Lf antisera. All sections were incubated at $4{ }^{\circ} \mathrm{C}$ with primary antisera overnight; successively, bridging antibody and PAP complex (DakoCytomation) for $30 \mathrm{~min}$ at RT were applied. For the demonstration of peroxidase activity the sections were incubated with 3,3'-diaminobenzidine tetrahydrochloride $-\mathrm{H}_{2} \mathrm{O}_{2}$ substrate solution for $10 \mathrm{~min}$ at $\mathrm{RT}$ in darkness. Finally, slides were slightly counterstained with Mayer's haematoxylin.

All series included positive tissue controls; for negative controls the step of incubation with the primary antibodies was omitted or replaced by phosphate-buffered saline.

Immunostained sections were estimated by light microscopy using an x20 and x40 objective lens and x10 eyepiece. Two pathologists using a double-headed microscope performed the assessment of immunostained sections on a consensus basis.

Quantification of Lf immunoreactivity was performed using the intensity-distribution (ID) score, a combined scoring system based on both the percentage of positive neoplastic cells (staining score) and the staining intensity of the tumour cell, similarly to that elsewhere reported (19). In detail, a staining score was estimated on a four-tiered scale: 0 (no staining); 1 (>0-5\%); 2 (>5-50\%); 3 (>50\%). Successively, the staining intensity, based on the predominant pattern present in the tumour, was graded as 1 (weak), 2 (moderate) or 3 (strong). Finally, the ID score was calculated by multiplying, for each case, the staining score by the staining intensity. A cut-off point was determined utilizing the median Lf ID-score value.

ER, PR and MIB-1 staining scores were evaluated by counting the percentage of positive nuclei per 1000 malignant cells in up to 10 fields representative of the whole neoplastic portions; all degrees of nuclear staining intensity were taken into consideration. Only specimens with an ER or PR staining score $>10 \%$ were considered positive. The median MIB-1 staining score value was utilized as a cut-off point to determine low and high Ki-67 expression.
Histochemical analysis. The AgNOR staining was performed according to guidelines of the Committee on AgNOR Quantification (20), as previously described (21). Successively, for each slide examined, microscopic fields representative of the lesions were assessed excluding, on the basis of the corresponding H\&E-stained section, any areas in which regressive changes, frank necrosis or technical artefacts were present. The mean area $\left(\mu \mathrm{m}^{2}\right)$ of AgNORs per cell (NORA) was evaluated at one focal plane with a $\mathrm{x} 40$ objective lens in at least 100 (mean 130) nuclei per specimens. Specific softwares, IM 5200 (Microscience Inc., Phoenix Technology Inc., Seattle, WA, USA) and AgNOR (Immagini e Computer, Rho-Milan, Italy), were used to determine mean NORA values per cell and per case, respectively. A cut-off point of $4.212 \mu \mathrm{m}^{2}$, previously determined by ourselves (22), was utilized to define low and high NORA values.

Statistical analysis. The possible correlations between Lf immunoexpression and clinicopathological parameters as well as ER and PR status and proliferative activity of EC were investigated using non-parametric methods (Mann-Whitney U test, Kruskal-Wallis H test).

Univariate survival analysis of time to death due to EC was performed by the Kaplan-Meier method, with the date of surgery as the entry date, while patients who died of other causes were censored. To compare the survival curves relative to different groups of patients, the Mantel-Cox log-rank test was applied. Successively, multivariate analysis (Cox regression model) was utilised to determine the independent effect of each variable on survival. In particular, forward stepwise procedure and likelihood ratio tests were used to select the variables included in the final model. With categorical variables, the deviation coding scheme was used. Prognostic variables with two or more categories of outcome were represented by a number of variables and parameters equal to the number of their categories, minus one; therefore, the reference category was not included as a variable. An estimation of the relative risk with $95 \%$ confidence interval was computed.

A probability $(\mathrm{P})$ value $<0.05$ was considered statistically significant. Data were analysed using the SPSS package version 6.1.3 (SPSS Inc., Chicago, IL).

\section{Results}

Lf immunoexpression was observed in $43 / 71$ cases $(61 \%)$ of EC. Lf positivity was localized in the cytoplasm (Fig. 1a and b), although a combined nuclear/cytoplasmic reactive pattern was also occasionally seen in neoplastic cells. Generally, immunoreactive neoplastic cells were found in direct contact with negative ones (Fig. 1a and b); the stroma, intermingled with neoplastic glands, sometimes showed stained leucocytes, which were also evident in Lf unreactive tumours (Fig. 1c), representing an internal staining control. Forty-one stained EC were of endometrioid type, showing a significantly higher Lf ID-score than non-endometrioid type $(\mathrm{P}=0.0418)$; in this latter group, only clear cell adenocarcinomas exhibited Lf expression. No relationship between Lf ID-score and age, histologic grade, stage and clinical course was revealed (Table I).

In EC, the immunostaining for ER and PR was heterogeneous; an immunopositivity in more than $10 \%$ of nuclei of 

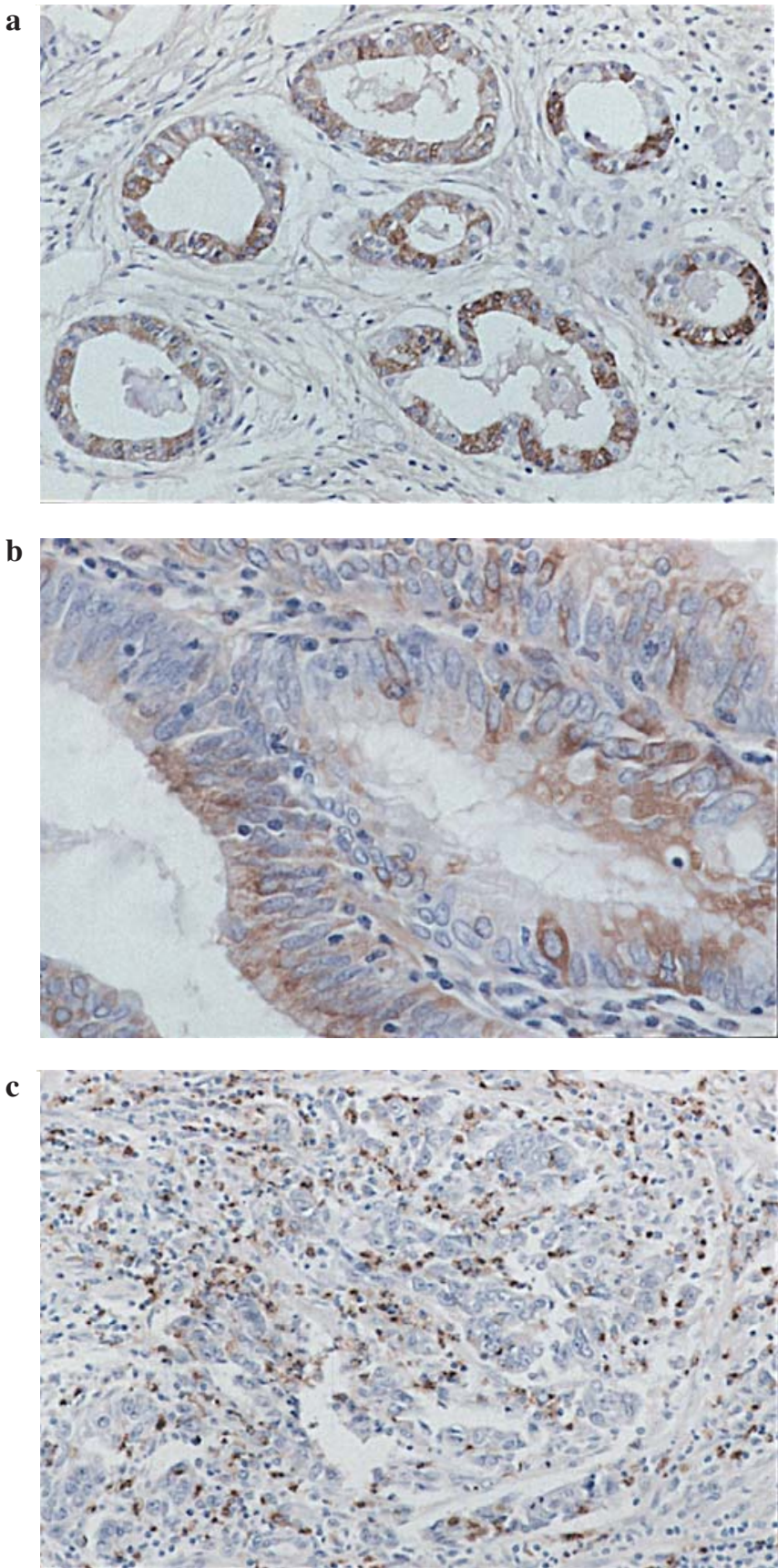

Figure 1. Immunoreactive cells are in contact with negative ones inside neoplastic endometrial glands (a, x120); note the intense cytoplasmic immunoreactivity (b, x157); in unreactive EC cases, the immunopositive neutrophils represent the internal staining control (c, x120) (Immunoperoxidase for Lf, Mayer's haemalum counterstain).

neoplastic cells was encountered in 45 and 39 cases for ER and PR, respectively. Moreover, a significantly higher Lf IDscore was encountered in ER-positive carcinomas (Table I).

A variously represented MIB-1 nuclear reactivity was found in EC, while no cytoplasmic staining was noted (Fig. 2). The rate of stained cells ranged from 2 to $88 \%$, with a median value of $17 \%$; 31 EC showed high MIB-1 values, whereas the remaining 40 carcinomas presented a staining score under the median value. No relationship between Lf and Ki-67 immunoexpression was appreciable (Table I).

In EC, the AgNORs showed an intranuclear localization and were clearly distinguishable as black dots also within

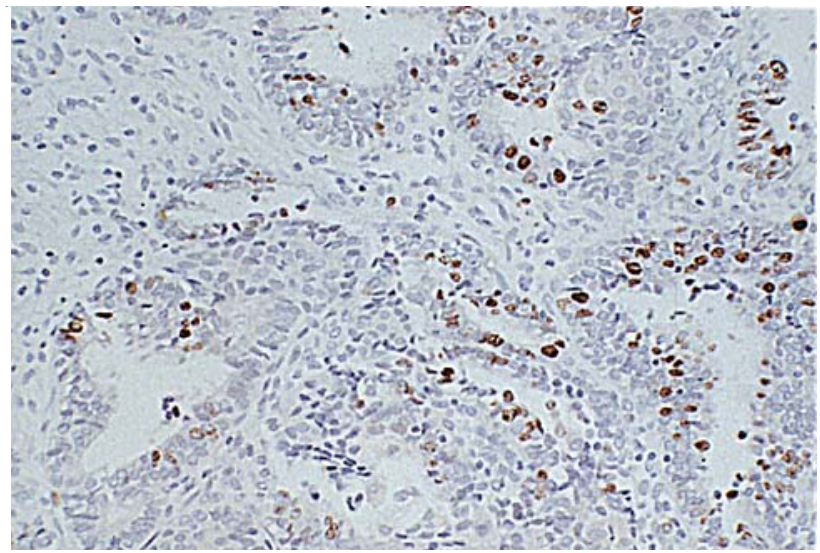

Figure 2. Nuclei of neoplastic EC glands showed an evident immunoreactivity for Ki-67 antigen (Immunoperoxidase for MIB-1, Mayer's haemalum counterstain, $\mathrm{x} 120)$.

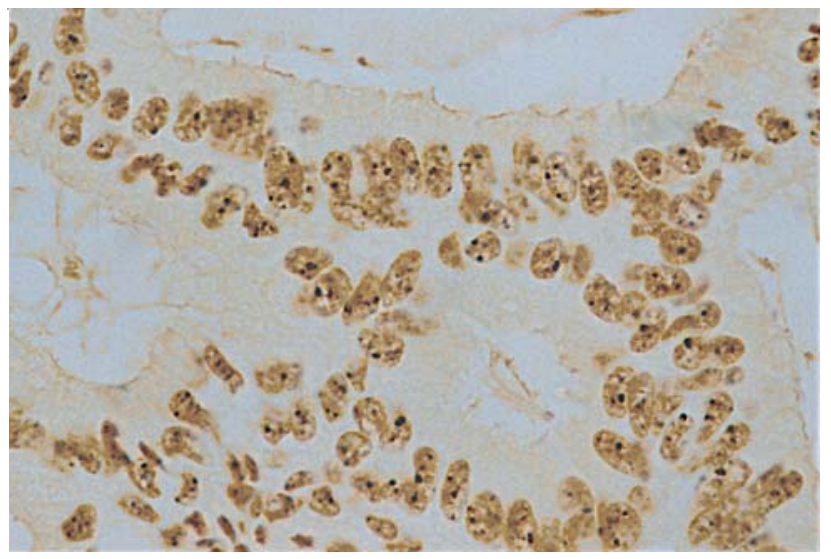

Figure 3. AgNORs are aggregate and scattered through the neoplastic nuclei, which show a round-to-oval shape in EC of endometrioid type (x157).

nucleoli (Fig. 3). The morphometric analysis was easily performed since an evident contrast between dark silver dots and nuclear background was appreciable. NORA values of neoplastic elements exhibited a normal distribution with a mean of $4.063( \pm 1.435) \mu \mathrm{m}^{2}$. The AgNOR quantity, espressed as NORA values, was unrelated to the Lf ID-score (Table I).

The follow-up time of patients ranged from 8 to 168 months (mean 82.5 months ); sixteen patients died of disease, while 55 were alive or censored. Data obtained by univariate analysis of all considered parameters concerning cancer-specific mortality in EC are reported in Table II. Among examined parameters, the architectural grade, the nuclear grade, the combined architectural/nuclear grade, the tumour stage, PR, Ki-67 and NORA showed significant P-values. However, by Cox multivariate analysis, NORA values and the tumour stage emerged as the only independent prognostic variables (Table III).

\section{Discussion}

Lf immunoreactivity has been detected in many human neoplasms such as adenocarcinomas of the parotid gland (23) and prostate $(24)$, breast carcinoma $(25,26)$, thyroid tumours 
Table I. Comparison of Lf ID-score among clinico-pathological parameters, ER and PR expression and proliferative activity.

\begin{tabular}{|c|c|c|c|c|c|c|}
\hline Parameter & No. of & cases $(\%)$ & Median & Range & Mean rank & P-value \\
\hline \multicolumn{6}{|l|}{ Age } & NS \\
\hline$\leq 50$ years & 5 & (7) & 0 & $(0-4)$ & 27.40 & \\
\hline$>50$ years & 66 & (93) & 1 & $(0-9)$ & 36.65 & \\
\hline \multicolumn{6}{|l|}{ Histotype } & 0.0418 \\
\hline Endometrioid & 64 & $(90)$ & 1.5 & $(0-9)$ & 37.59 & \\
\hline Non-endometrioid & 7 & $(10)$ & 0 & $(0-2)$ & 21.50 & \\
\hline \multicolumn{7}{|l|}{ Histologic grade } \\
\hline \multicolumn{6}{|l|}{ Architectural } & NS \\
\hline Grade 1 & 44 & $(62)$ & 1 & $(0-9)$ & 35.80 & \\
\hline Grade 2 & 16 & $(23)$ & 1.5 & $(0-6)$ & 39.81 & \\
\hline Grade 3 & 11 & $(15)$ & 1 & $(0-3)$ & 31.27 & \\
\hline \multicolumn{6}{|l|}{ Nuclear } & NS \\
\hline Grade 1 & 19 & $(27)$ & 2 & $(0-9)$ & 40.55 & \\
\hline Grade 2 & 35 & $(49)$ & 1 & $(0-6)$ & 34.76 & \\
\hline Grade 3 & 17 & $(24)$ & 1 & $(0-6)$ & 33.47 & \\
\hline \multicolumn{6}{|l|}{ Combined } & NS \\
\hline Grade 1 & 40 & $(56)^{\mathrm{a}}$ & 1.5 & $(0-9)$ & 37.17 & \\
\hline Grade 2 & 13 & $(18)^{\mathrm{a}}$ & 1 & $(0-6)$ & 35.88 & \\
\hline Grade 3 & 18 & $(25)^{\mathrm{a}}$ & 1 & $(0-6)$ & 33.47 & \\
\hline \multicolumn{6}{|l|}{ Stage } & NS \\
\hline I & 48 & $(68)$ & 1 & $(0-9)$ & 35.86 & \\
\hline II & 12 & $(17)$ & 1 & $(0-6)$ & 34.46 & \\
\hline III & 8 & $(11)$ & 1.5 & $(0-4)$ & 34.75 & \\
\hline IV & 3 & $(4)$ & 4 & $(0-6)$ & 47.67 & \\
\hline \multicolumn{6}{|l|}{ Clinical course } & NS \\
\hline Alive & 55 & $(77)$ & 1 & $(0-9)$ & 35.82 & \\
\hline Died of disease & 16 & (23) & 1.5 & $(0-6)$ & 36.63 & \\
\hline \multicolumn{6}{|l|}{ ER } & 0.0051 \\
\hline Negative & 26 & $(37)$ & 0 & $(0-6)$ & 27.33 & \\
\hline Positive & 45 & (63) & 2 & $(0-9)$ & 41.01 & \\
\hline \multicolumn{6}{|l|}{ PR } & 0.0516 \\
\hline Negative & 32 & $(45)$ & 0 & $(0-6)$ & 30.94 & \\
\hline Positive & 39 & $(55)$ & 2 & $(0-9)$ & 40.15 & \\
\hline \multicolumn{6}{|l|}{$\mathrm{Ki}-67$} & NS \\
\hline Low & 40 & $(56)$ & 1 & $(0-4)$ & 33.88 & \\
\hline High & 31 & $(44)$ & 2 & $(0-9)$ & 38.74 & \\
\hline \multicolumn{6}{|l|}{ NORA } & NS \\
\hline Low & 43 & (61) & 2 & $(0-9)$ & 38.23 & \\
\hline High & 28 & (39) & 0.5 & $(0-6)$ & 32.57 & \\
\hline
\end{tabular}

NS, not significant. ${ }^{a}$ Figures do not amount to $100 \%$ because of rounding of error.

(27-30), renal cell carcinoma (31), gastric (32) and colorectal adenomas and carcinomas (33), gallbladder carcinomas (34), astrocytomas and multiforme glioblastomas (35) and, recently, in skin nevi and melanomas (36); nevertheless, in these neo- plastic conditions, the functional role of Lf has not been fully elucidated.

Although Walmer et al (12) have already shown the Lf immunoexpression in $66 \%$ of 12 unspecified endometrial 
Table II. Prognostic parameters examined in endometrial carcinomas: a univariate analysis to cancer-specific mortality by Mantel-Cox log-rank test.

\begin{tabular}{lrcc}
\hline Parameter & \multicolumn{1}{c}{$\chi^{2}$} & DF & P-value \\
\hline Age & 1.40 & 1 & $\mathrm{NS}$ \\
Histotype & 0.26 & 1 & $\mathrm{NS}$ \\
Architectural grade & 9.81 & 2 & 0.0074 \\
Nuclear grade & 13.34 & 2 & 0.0013 \\
Combined grade & 13.51 & 2 & 0.0012 \\
Stage & 17.29 & 3 & 0.0006 \\
ER & 1.94 & 1 & $\mathrm{NS}$ \\
PR & 4.90 & 1 & 0.0269 \\
Ki-67 & 7.29 & 1 & 0.0070 \\
NORA & 23.02 & 1 & 0.0000 \\
Lf & 0.03 & 1 & $\mathrm{NS}$ \\
\hline
\end{tabular}

NS, not significant; DF, degree of freedom.

Table III. Multivariate survival analysis by Cox regression model in endometrial carcinomas.

\begin{tabular}{lccccc}
\hline Variable & Category & $\beta$ & SE & $\operatorname{Exp}(\beta)$ & P-value \\
\hline NORA & & 1.408 & 0.391 & 4.090 & 0.0003 \\
Stage & & & & & \\
& II & -0.023 & 0.502 & 0.976 & 0.9620 \\
& III & 0.532 & 0.426 & 1.702 & 0.2124 \\
& IV & 0.840 & 0.609 & 2.317 & 0.1679 \\
\hline
\end{tabular}

$\beta$, regression coefficient; $S E$, standard error; $\operatorname{Exp}(ß)$, ratio of risk.

adenocarcinomas, we report herein Lf immunoreactivity in a larger casuistry of EC, taking also into consideration their histotype. In particular, our findings have documented a similar Lf immunoreactivity in $61 \%$ of $71 \mathrm{EC}$, mainly in endometrioid type, whereas among the non-endometrioid ones only clear cell adenocarcinomas are reactive. The Lf localization is revealed in the cytoplasm of neoplastic cells and only sometimes in the nucleus. In our opinion, the site of Lf immunoreactivity both in the nucleus and cytoplasm is not surprising, since this secretory protein has been previously detected also in the nucleus, mainly in nucleoli, and it has been thought to be involved in ribosomal biogenesis $(37,38)$. On the other hand, after its transport into the nucleus, $\mathrm{Lf}$ is able to bind to specific DNA sequences, thus activating transcription (38).

In EC, malignant transformation of the endometrium is associated with the up-regulation of Lf mRNA and protein biosynthesis (12). Although some different hypotheses have been claimed in order to explain the presence of Lf in EC (12), the significant degree of Lf immunoexpression in our series of endometrioid carcinomas may be linked to the action of estrogens, since a significantly higher Lf ID-score was encountered in ER-positive carcinomas. On the other hand, it is well known that the endometrioid type of EC represents a slowly developing indolent form which develops in the setting of excess oestrogen stimulation $(17,39)$. Sequencing data have suggested that the promoter for the human Lf gene contains an estrogen response element $(16,40)$; moreover, by immunohistochemistry, Lf expression was undetectable in the untreated ovariectomized monkey endometrium, but it was elevated by oestrogen treatment (16). In the present study of EC, we have observed an evident direct correlation between the expression of Lf and ER, while only a tendency towards a linear relationship between Lf and PR has been found; this latter finding is in contrast with that reported in the literature (12), but this difference could be due to the large number of patients enrolled in our study.

In vitro studies have demonstrated that $\mathrm{Lf}$ possesses a cell proliferation effect in human endometrial stromal cells (15), although this proliferative effect could be due to the transport of iron into cells or, alternatively, to a modulatory effect on the action of growth factors $(15,41)$. However, in our series of EC, no correlations have been found between Lf immunoexpression and neoplastic proliferation, either expressed as growth fraction (MIB-1) or as cell cycle speed (AgNOR). This finding is not surprising, since it has been reported that Lf inhibits epithelial cell proliferation and suppresses tumour growth in vitro by blocking the cell cycle progression $(42,43)$. Lf appears to exert its anti-proliferative effect by a modulation of proteins which regulate the G1 to S transition (43); moreover, a possible anti-tumour activity for Lf has been proposed in experimental and clinical studies for cancer prevention (44), even if this effect remains highly controversial. In fact, it has been demonstrated that exogenous Lf enhanced cell proliferation in both normal human epithelial cells and EC cell lines (45); in the same study, it has been shown that tamoxifen greatly increased the evidence of Lf in EC cells, not affecting cell growth (45). Therefore, it has been proposed that stable expression of Lf protein may impart a survival advantage to EC cells, which may, in part, account for the resistance of these cells to tamoxifen (45). On the other hand, we can not exclude that the immunoexpression of $\mathrm{Lf}$ in cases of EC could be related to the well-known affinity for iron by Lf in itself, since iron has been considered an essential nutrient for dividing cells $(46,47)$; therefore, under functional conditions such as endocrine stimuli, neoplastic cells should be able to produce Lf in order to have a greater availability of iron for their turnover, similarly to that elsewhere suggested in other neoplasms $(27,34-36)$.

In an attempt to settle the significance of Lf in the clinical management of patients affected by EC, we have performed survival analysis taking into consideration many clinicopathological and morphofunctional parameters. Our univariate analysis of cancer-specific mortality in EC indicates the architectural, nuclear and combined histologic grades as well as the stage, PR, Ki-67 and NORA as significant parameters, while Lf immunoexpression is not useful for prognostic purposes; in addition, multivariate analysis clearly documented that only NORA and tumour stage were independent variables in EC, as previously reported elsewhere (22). 
In conclusion, on the basis of all aforementioned considerations, the utilization of Lf as a prognostic marker, able to identify patients at different risk of death, or alternatively, its clinical application as a therapeutic agent, require further validation and must be considered with great caution. In fact, at present, recombinant human Lf is becoming available for evaluation for possible prophylactic or therapeutic use in a wide variety of human medical conditions (48). Moreover, although Lf is a human natural product efficiently metabolized with no side effects, precaution is needed to avoid antigenic sensitization as well as its interaction with specific protozoa or bacteria that utilize Lf in their acquisition of host iron.

\section{References}

1. Johansson BG: Isolation of an iron containing red protein from human milk. Acta Chem Scand 14: 510-512, 1960.

2. Metz-Boutigue MH, Jolles J, Mazurier J, et al: Human lactotransferrin: amino acid sequence and structural comparison with other transferrins. Eur J Biochem 145: 659-676, 1984.

3. Anderson BF, Baker HM, Dodson EJ, et al: Structure of human lactoferrin at 3.2 - a resolution. Proc Natl Acad Sci USA 84: 1769-1773, 1987.

4. Masson PL, Heremans JF and Dire CH: An iron-binding protein common to many external secretions. Clin Chim Acta 14: 735-739, 1966.

5. De Vet BJCM and van Gool J: Lactoferrin and iron absorption in the small intestine. Acta Med Scand 196: 393-402, 1974.

6. Mason DY and Taylor CR: Distribution of transferrin, ferritin and lactoferrin human tissues. J Clin Pathol 31: 316-327, 1978.

7. Brock JH: Lactoferrin in human milk: its role in iron absorption and protection against enteric infection in the newborn infant. Arch Dis Child 55: 417-421, 1980.

8. Reitamo S, Kontinnen YT and Segerber-Kontinnen M: Distribution of lactoferrin in human salivary glands. Histochemistry 66: 285-291, 1980.

9. Korsrud FR and Brandtzaeg P: Characterization of epithelial elements in human major salivary glands by functional markers: localization of amylase, lactoferrin, lysozyme, secretory component and secretory immunoglobulins by paired immunofluorescence staining. J Histochem Cytochem 30: 657-666, 1982.

10. Cohen MS, Britigan BE, French M, et al: Preliminary observations on lactoferrin secretion in human vaginal mucus: variation during the menstrual cycle, evidence of hormonal regulation, and implications for infection with Neisseria gonorrhoeae. Am J Obstet Gynecol 157: 1122-1125, 1987.

11. Tedeschi A, Tuccari G, Magazzu G, et al: Immunohistochemical localization of lactoferrin in duodenojejunal mucosa from celiac children. J Pediatr Gastroenterol Nutr 6: 328-334, 1987.

12. Walmer DK, Padin CJ, Wrona MA, et al: Malignant transformation of the human endometrium is associated with overexpression of lactoferrin messenger RNA and protein. Cancer Res 55: 1168-1175, 1995.

13. Kelver ME, Kaul A, Nowicki B, et al: Estrogen regulation of lactoferrin expression in human endometrium. Am J Reprod Immunol 36: 243-247, 1996.

14. Yamashita S: Immunohistochemical study of estrogen-induced lactoferrin-like protein in the mouse uterus: localization in the nucleolus and secretory pathway. Acta Histochem Cytochem 28: 217-225, 1995.

15. Yanaihara A, Toma Y, Saito H, et al: Cell proliferation effect of lactoferrin in human endometrial stroma cells. Mol Hum Reprod 6: 469-473, 2000.

16. Teng CT, Gladwell W, Beard C, et al: Lactoferrin gene expression is estrogen responsive in human and rhesus monkey endometrium. Mol Hum Reprod 8: 58-67, 2002.

17. Tavassoli FA and Devilee P (eds). Pathology and genetics of tumours of the breast and female genital organs. World Health Organization Classification of Tumours. IARC Press, Lyon, 2000.

18. Zaino RJ, Kurman RJ, Diana KL, et al: The utility of the revised international federation of gynecology and obstetrics histologic grading of endometrial adenocarcinoma using a defined nuclear grading system. Cancer 75: 81-86, 1995.
19. Tuccari G, Villari D, Giuffrè G, et al: Immunohistochemical evidence of lactoferrin in hepatic biopsies of patients with viral or cryptogenetic chronic liver disease. Histol Histopathol 17: 1077-1083, 2002.

20. Öfner D, Aubele M, Biesterfeld S, et al: Guidelines of AgNOR quantification - first update. In: Cell Proliferation Assessment in Oncology. Hofstadter F, Knuchel R and Rüschoff J (eds). Virchows Arch 427: 341, 1995.

21. Giuffrè G, Caruso RA, Barresi G, et al: Prognostic significance of standardized AgNOR analysis in early and advanced gastric carcinomas. Virchows Arch 433: 261-266, 1998.

22. Giuffrè G, Fulcheri E, Gualco M, et al: Standardized AgNOR analysis as a prognostic parameter in endometrial carcinoma, endometrioid type. Analyt Quant Cytol Histol 23: 31-39, 2001.

23. Caselitz J, Jaup T and Seifert G: Lactoferrin and lysozyme in carcinomas of the parotid gland. Virchows Arch (A) 394: 61-73, 1981.

24. Barresi G and Tuccari G: Lactoferrin in benign hypertrophy and carcinomas of the prostatic gland. Virchows Arch (A) 403: 59-66, 1984.

25. Rossiello R, Carriero MV and Giordano GG: Distribution of ferritin, transferrin and lactoferrin in breast carcinoma tissue. $\mathrm{J}$ Clin Pathol 37: 51-55, 1984.

26. Charpin C, Lachard A, Pourreau-Schneider N, et al: Localization of lactoferrin and non-specific cross-reacting antigen in human breast carcinomas. Cancer 55: 2612-2617, 1985 .

27. Tuccari $\mathrm{G}$ and Barresi G: Immunohistochemical demonstration of lactoferrin in follicular adenomas and thyroid carcinomas. Virchows Arch (A) 406: 67-74, 1985.

28. Barresi $\mathrm{G}$ and Tuccari G: Iron-binding proteins in thyroid tumours. An immunocytochemical study. Path Res Pract 182: 344-351, 1987.

29. Cabaret V, Vilain MO, Delobelle-Deroide A, et al: Détection immunohistochimique de la céruloplasmine et de la lactoferrine sur une sèrie de 59 tumeurs thyroidiennes. Ann Pathol 12: 347-352, 1992.

30. Asato de Camargo RY, Longatto Filho A, Ferreira Alves VA, et al: Lactoferrin in thyroid lesions. Immunoreactivity in fine needle aspiration biopsy samples. Acta Cytol 40: 408-413, 1996.

31. Loughlin KR, Gittes RF and Partridge D: The relationship of lactoferrin to the anemia of renal carcinoma. Cancer 59: 566-571, 1987.

32. Tuccari G, Barresi G, Arena F, et al: Immunocytochemical detection of lactoferrin in human gastric carcinomas and adenomas. Arch Pathol Lab Med 113: 912-916, 1989.

33. Tuccari G, Rizzo A, Crisafulli C, et al: Iron binding proteins in human colorectal adenomas and carcinomas: an immunocytochemical investigation. Histol Histopathol 7: 543-547, 1992.

34. Tuccari G, Rossiello R and Barresi G: Iron binding proteins in gallbladder carcinomas. An immunocytochemical investigation. Histol Histopathol 12: 671-676, 1997.

35. Tuccari G, Giuffrè G, Crisafulli C, et al: Immunohistochemical detection of lactoferrin in human astrocytomas and multiforme glioblastomas. Eur J Histochem 43: 317-322, 1999.

36. Tuccari G, Giuffrè G, Scarfî R, et al: Immunolocalization of lactoferrin in surgically resected pigmented skin lesions. Eur J Histochem 49: 33-38, 2005.

37. Garrè C, Bianchi-Scarra G, Sirito M, et al: Lactoferrin binding sites and nuclear localization in K562(S) cells. J Cell Physiol 153: 477-482, 1992.

38. Penco S, Scarfî S, Giovine M, et al: Identification of an import signal for, and the nuclear localization of, human lactoferrin. Biotechnol Appl Biochem 34: 151-159, 2001.

39. Sherman ME, Bur ME and Kurman RJ: p53 in endometrial cancer and its putative precursors: evidence for diverse pathways of tumorigenesis. Hum Pathol 26: 1268-1274, 1995.

40. Teng CT, Liu Y, Yang N, et al: Differential molecular mechanism of estrogen action that regulates lactoferrin gene in human and mouse. Mol Endocrinol 6: 1969-1981, 1992.

41. Hagiwara T, Shinoda I, Fukuwatari Y, et al: Effects of lactoferrin and its peptides on proliferation of rat intestinal epithelial cell line, IEC-18, in the presence of epidermal growth factor. Biosci Biotechnol Biochem 59: 1875-1881, 1995.

42. Damiens E, Mazurier J, El Yazidi I, et al: Effects of human lactoferrin on NK cell cytotoxicity against haematopoietic and epithelial tumour cells. Biochim Biophys Acta 1402: 277-287, 1998. 
43. Damiens E, El Yazidi I, Mazurier J, et al: Lactoferrin inhibits G1 cyclin-dependent kinases during growth arrest of human breast carcinoma cells. J Cell Biochem 74: 486-498, 1999.

44. Tsuda H, Sekine K, Fujita K, et al: Cancer prevention by bovine lactoferrin and underlying mechanisms - a review of experimental and clinical studies. Biochem Cell Biol 80: 131-136, 2002.

45. Albright CD and Kaufman DG: Lactoferrin: a tamoxifenresponsive protein in normal and malignant human endometrial cells in culture. Exp Mol Pathol 70: 71-76, 2001.
46. Weinberg ED: Iron withholding: a defense against infection and neoplasia. Physiol Rev 64: 65-102, 1984.

47. Shoji A and Ozawa E: Necessity of transferrin for RNA synthesis in chick myotubes. J Cell Physiol 127: 349-356, 1986.

48. Weinberg ED: Human lactoferrin: a novel therapeutic with broad spectrum potential. J Pharm Pharmacol 53: 1303-1310, 2001. 